\title{
The influence of fractional pulse pressure on the outcome of pulmonary thromboendarterectomy
}

\author{
N. Tanabe*, O. Okada*, Y. Abe*, M. Masuda\#, N. Nakajima\#, T. Kuriyama*
}

\begin{abstract}
The influence of fractional pulse pressure on the outcome of pulmonary thromboendarterectomy. N. Tanabe, O. Okada, Y. Abe, M. Masuda, N. Nakajima, T. Kuriyama. (C) ERS Journals Ltd 2001.

ABSTRACT: Although pulmonary thromboendarterectomy is an effective modality for the treatment of chronic thromboembolic pulmonary hypertension (CTEPH), the mortality in patients with severe haemodynamic disease is still high. Recently it was reported that fractional pulse pressure (pulmonary arterial pulse pressure/mean pulmonary arterial pressure) was higher in CTEPH than in primary pulmonary hypertension (PPH). It was hypothesized that fractional pulse pressure might be low in CTEPH with inaccessible distal thrombi and/or secondary pulmonary hypertensive change, resulting to the high operative mortality.

To determine the influence of fractional pulse pressure to the outcome of surgery, 32 patients with CTEPH who had thromboendarterectomy between 1985 and 1998 were studied. Pulmonary haemodynamics and fractional pulse pressure were compared between survivors $(n=26)$ and nonsurvivors $(n=6)$ postoperatively. Those parameters in PPH $(n=18)$ and large vessel pulmonary arteritis $(n=6)$ were also analysed.

Fractional pulse pressure in CTEPH (1.23 \pm 0.21$)$ was significantly higher than in PPH $(0.93 \pm 0.22 ; p=0.0017)$ and lower than in pulmonary arteritis $(1.69 \pm 0.32$; $p=0.03)$. Fractional pulse pressure in survivors $(1.26 \pm 0.21)$ was significantly higher than in nonsurvivors $(1.06 \pm 0.16 ; p=0.03)$. Fractional pulse pressure is a significant predictor for mortality in patients with high pulmonary vascular resistance $>1100$ dynes $\cdot \sec \cdot \mathrm{cm}^{-5}$.

To conclude fractional pulse pressure in addition to pulmonary vascular resistance might be useful in predicting for the outcome of surgery, especially in patients with severe haemodynamic impairment.
\end{abstract}

Eur Respir J 2001; 17: 653-659.

\author{
*Dept of Chest Medicine and ${ }^{\#}$ First \\ Dept of Surgery, Chiba University \\ School of Medicine, Japan. \\ Correspondence: N. Tanabe \\ Dept of Chest Medicine \\ Chiba University School of Medicine \\ 1-8-1 Inohana Chuou-ku \\ Chiba $260-8670$ \\ Japan. \\ Fax: 81432262176
}

Keywords: Chronic thromboembolic pulmonary hypertension prognosis

pulmonary hypertension

pulmonary thromboendarterectomy pulse pressure

Received: November 251999

Accepted after revision October 102000

This study was supported in part by a Research Grant for intractable Diseases from the ministry of Health and Welfare, Japan.
Although pulmonary thromboendarterectomy is an effective modality for the treatment of chronic thromboembolic pulmonary hypertension (CTEPH) [1-15], the mortality in patients with high pulmonary vascular resistance is still high $[8,9]$. The inability to reduce pulmonary vascular resistance is a major risk factor associated with high mortality $[4,9]$.

Chronic pulmonary hypertension of any origin frequently results in pathological change in the proximal (elastic) and distal (resistive) pulmonary vasculature. The obstruction or significant stenosis of large pulmonary artery increased pulse pressure (systolic pressurediastolic pressure) as well as characteristic impedance, and reduced wave reflection $[16,17]$. GRANT et al. [16] reported that the degree of the right ventricular hypertrophy was dependent on the increase in pulse pressure rather than the increase in mean pulmonary arterial pressure $[16,18]$. However, primary pulmonary hypertension (PPH) and CTEPH generally induce severe haemodynamic disturbances in accordance to the increase of pulmonary vascular resistance or mean pulmonary arterial pressure compared to unilateral pulmonary arterial occlusion. Consideration of both impedance (i.e. the opposition to the pulsatile components of flow) and pulmonary vascular resistance (i.e. the opposition to the mean components of flow) are required to evaluate the right ventricular afterload, and these two measurements among pulmonary hypertensive diseases are thought to be different because of the different location of involved lesions in pulmonary arterial trees.

Recently it was reported that the pulsatility as the ratio of pulse pressure to mean pressure (i.e. fractional pulse pressure of the pulmonary artery: PPf) in CTEPH was larger than in PPH, because of the difference of involved pathology [19]. They hypothesized and explained their findings in the following way. In CTEPH, thrombi obstruct the proximal arteries preferentially (i.e. from the main pulmonary artery to segmental arteries). Therefore, it is likely that the thrombi attached to the proximal arteries mechanically stiffen the arterial wall and increase proximal resistance without comparably increasing peripheral arterial resistance. In contrast, PPH primarily involves peripheral segment of pulmonary arterial trees. The vascular change in $\mathrm{PPH}$ would increase peripheral arterial resistance. Increases 
in stiffness and resistance in the proximal arteries would increase pulse pressure, whereas those in peripheral arteries increase mean arterial pressure.

It is hypothesized that PPf might be low in CTEPH with inaccessible distal thrombi and/or secondary pulmonary hypertensive changes [20], resulting to the high operative mortality.

In the present report, the influence of PPf on the outcome of surgery in CTEPH was retrospecitvely investigated, and the usefulness of PPf in the differential diagnosis between CTEPH and other pulmonary hypertensive diseases (PPH and large vessel pulmonary arteritis with central pulmonary arterial stenosis [21-25]) was reassessed.

\section{Patients and methods}

A total of 32 patients with CTEPH (22 females, 10 males; mean \pm SD age $51 \pm 13$, range $22-73$ ) were operated on between April 1985 and March 1998 at Chiba University Hospital. CTEPH was defined as mean pulmonary arterial pressure (mean $P$ pa) $\geqslant 25 \mathrm{mmHg}$ with a mean pulmonary arterial wedge pressure $<12 \mathrm{mmHg}$ in patients who had dyspnoea on exertion for a duration of $>6$ months. In addition, lung perfusion scans were required to show segmental or larger defect concomitant with normal ventilation scan study. Finally, thromboembolic obstruction was confirmed by pulmonary angiography [26].

The selection criteria for pulmonary thromboendarterectomy were slightly modified from those defined by Moser et al. [3]. The criteria were as follows [9]: 1) mean $P$ pa $\geqslant 30 \mathrm{mmHg}$, resulting in calculated pulmonary vascular resistance (PVR) $>300$ dynes $\cdot \mathrm{sec} \cdot \mathrm{cm}^{-5}$ even after oral anticoagulant therapy for $>6$ months; 2) dyspnoea on exertion according to Fletcher and HughJones classification (H-J) [27] $\geqslant$ grade $3 ; 3$ ) thrombi defined as accessible to current surgical technique (main, lobar, segmental arteries); 4) the absence of severe associated disease.

During the same period, 18 patients were diagnosed as PPH (13 females, five males; mean age $37 \pm 11 \mathrm{yrs,}$ range 16-64), and six patients (five females, one male; mean age $53 \pm 10$ yrs, range $38-67$ ) were diagnosed as large vessel pulmonary arteritis with central pulmonary arterial stenosis. $\mathrm{PPH}$ was defined as mean $P$ pa $\geqslant 25$ $\mathrm{mmHg}$ with mean pulmonary wedge pressure $<12$ $\mathrm{mmHg}$. Other possible aetiologies of pulmonary hypertension, such as mitral valve diseases, congenital heart failure, left ventricular failure, collagen vascular disease, and portal hypertension were excluded. In addition, lung perfusion scans were required to show normal or small patchy perfusion defects without larger than segmental defects concomitant with normal ventilation scans. Six patients with large vessel pulmonary arteritis were confirmed by pulmonary angiograms with the findings of central (main or lobar) arterial stenosis. Of that group, three patients were associated with Takayasu's arteritis with systemic arterial involvement [23-25] and the remaining three patients were thought to have idiopathic isolated pulmonary arteritis without any systemic arterial involvement $[18,19]$.

\section{Measurement of haemodynamic variables}

Haemodynamic variables were measured in supine position while breathing room air. After venous access was achieved via internal jugular vein, right-side heart catheterization was performed using a fluid-filled system that included a balloon-tipped, flow-directed catheter (7.5 F Swan-Ganz catheter). Transducers were positioned at the mid-axillary line and zeroed at atmospheric pressure. The measurement of pulmonary arterial pressure was performed in the pulmonary arterial trunk proximal to stenotic lesions by thrombi or vasculitis. Six waves including three waves at endexpiration were recorded. A hard copy was made of the pressure tracing using a chart recorder at a paper speed of $50 \mathrm{~mm} \cdot \mathrm{s}^{-1}$. Cardiac output $\left(Q^{\prime}\right)$ was measured in triplicate by the thermodilution technique. Cardiac index (CI) was calculated as $Q^{\prime}$ divided by body surface area. PVR was calculated conventionally as the ratio of the difference between mean $P$ pa and pulmonary wedge pressure to $Q^{\prime}$.

\section{Fractional pulse pressure}

As shown in figure 1, the pulsatility as the ratio of pulse pressure to mean $P$ pa (fractional pulse pressure: PPf) was characterized according to those by NAKAYAMA et al. [19], while mean $P$ pa was calculated by the integration from the pressure wave at a sampling rate of 250 points per second. Three waves at end-expiration were used for calculating PPf.

\section{Pulmonary thromboendarterectomy}

In 16 cases, a lateral thoracotomy [9-14] to one lung was used, which contained the dominant thrombus judged by ventilation-perfusion scans and pulmonary arteriogram.

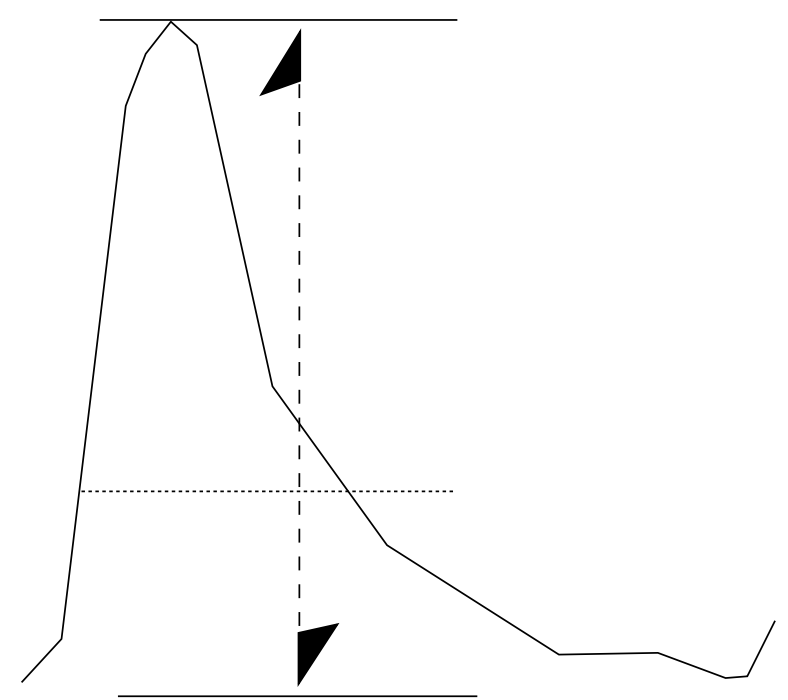

Fig. 1. - Schematic representation of waveform. Fractional pulse pressure $(\mathrm{PPf})$ is calculated as $\mathrm{PPf}=$ pulse pressure/mean $P$ pa and is indicated by the dashed vertical line. PPf is the ratio of pulse pressure to mean pulmonary arterial pressure $(\cdots \cdots)$ according to NAKAYAMA et al. [19]. 
In 16 cases, a median sternotomy with the use of deep hypothermia and circulatory arrest [1-10] was used. Although 14 patients were endarterectomized bilaterally, the remaining two patients were endarterectomized unilaterally, because thrombi on the contralateral side were located too distal $[9,15]$.

As for the period of time, 14 patients (three with median sternotomy; 11 with lateral thoracotomy) were operated on between 1986 and 1991, and 18 (thirteen with median sternotomy; five with lateral thoracotomy) were operated from 1992.

In all patients, inferior vena cava filters were placed postoperatively unless a previous interruptive procedure had been done.

\section{Analysis}

PPf and cardiorespiratory variables were compared between CTEPH, PPH and pulmonary arteritis to reassess the usefulness of this parameter for the differential diagnosis of pulmonary hypertensive diseases. In CTEPH who had pulmonary thromboendarterectomy, PPf, other preoperative parameters, and operative approach were compared between survivors and nonsurvivors who died within 30 days after surgery. In the limited patients with high PVR $\left(>1,100\right.$ dynes $\left.\cdot \mathrm{sec} \cdot \mathrm{cm}^{-5}\right)$, those parameters were also compared between survivors and nonsurvivors. To know whether PPf is a better predictor for mortality than PVR or not, correlation coefficient between them was calculated, and if it was not significant, both were included in the multivariate logistic regression analysis for operative mortality.

\section{Statistical analysis}

Values are presented as means \pm SD. Comparisons of three groups (CTEPH, PPH, pulmonary arteritis) were performed by a nonparametric Kruskal-Wallis analysis of variance with Sheffe's test for multiple comparisons.
Comparisons between survivors and nonsurvivors were made using a Mann-Whitney U-test and Chi-squared test, as appropriate. A $\mathrm{p}<0.05$ was taken as statistically significant.

\section{Results}

The cardiorespiratory variables of three groups are shown in table 1. The mean age in PPH was younger than in CTEPH or pulmonary arteritis. Arterial oxygen tension $\left(\mathrm{Pa}, \mathrm{O}_{2}\right)$ in $\mathrm{CTEPH}$ was lower than in others, while arterial carbon dioxide tension $\left(\mathrm{Pa}, \mathrm{CO}_{2}\right)$ in CTEPH and $\mathrm{PPH}$ was lower than in pulmonary arteritis. Mean and diastolic $P$ pa, and PVR in CTEPH were lower than in $\mathrm{PPH}$, while systolic $P$ pa, and $\mathrm{CI}$ in CTEPH were similar to in PPH. Systolic, mean, diastolic $P$ pa and PVR in pulmonary arteritis were significantly lower than in others.

Illustrated in figure 2 are the examples of waveforms and angiographic findings of pulmonary artery for PPH, pulmonary arteritis, CTEPH (survivors, nonsurvivors). The waveforms between PPH and pulmonary arteritis were different, and PPf in PPH (0.59) was lower than in pulmonary arteritis (1.72). The angiogram in pulmonary arteritis showed complete obstruction of the right main pulmonary artery and stenosis of the left lower branch, while the angiogram in PPH showed marked pruning of the distal vessels.

As shown in table 1 and figure 3, mean value of PPf in CTEPH $(1.23 \pm 0.21)$ was significantly $(\mathrm{p}=0.017)$ higher than in PPH $(0.93 \pm 0.22)$ and significantly $(\mathrm{p}=$ $0.033)$ lower than in pulmonary arteritis $(1.69 \pm 0.32)$. The distribution of PPfs in CTEPH was wide and overlapped with the distribution of PPfs in PPH.

In CTEPH who had pulmonary thromboendarterectomy, 24 patients survived and their pulmonary haemodynamics significantly improved (mean $P$ pa preoperative: $46.1 \pm 7.8$; postoperative: $28.6 \pm 8.1 \mathrm{mmHg}$, PVR preoperative: $815 \pm 270$; postoperative: $377 \pm 165$ dynes $\left.\cdot \mathrm{sec} \cdot \mathrm{cm}^{-5}\right)$. Six deaths $(18.8 \%)$ occurred within 30 days after surgery. The mortality for surgery was $21.5 \%$

Table 1. - Comparison of cardiorespiratory data

\begin{tabular}{|c|c|c|c|c|c|c|}
\hline \multirow{2}{*}{ Parameter } & \multirow{2}{*}{$\begin{array}{c}\text { CTEPH } \\
1\end{array}$} & \multirow{2}{*}{$\begin{array}{c}\mathrm{PPH} \\
2\end{array}$} & \multirow{2}{*}{$\begin{array}{c}\text { Pulmonary arteritis } \\
3\end{array}$} & \multicolumn{3}{|c|}{ p-value* } \\
\hline & & & & 1 versus 2 & 1 versus 3 & 2 versus 3 \\
\hline Subjects $\mathrm{n}$ & 32 & 18 & 6 & & & \\
\hline Age yrs & $51 \pm 13$ & $37 \pm 11$ & $53 \pm 10$ & 0.0014 & 0.92 & 0.03 \\
\hline Mean $P$ pa $\mathrm{mmHg}$ & $46 \pm 9$ & $54 \pm 13$ & $28 \pm 13$ & 0.12 & 0.046 & 0.0015 \\
\hline Systolic $P$ pa mmHg & $83 \pm 17$ & $88 \pm 20$ & $60 \pm 35$ & & NS & \\
\hline Diastolic $P$ pa $\mathrm{mmHg}$ & $27 \pm 6$ & $39 \pm 12$ & $11 \pm 5$ & 0.0034 & 0.011 & $<0.0001$ \\
\hline CI $\mathrm{L} \cdot \mathrm{min}^{-1} \cdot \mathrm{m}^{-2}$ & $2.5 \pm 0.5$ & $2.3 \pm 0.6$ & $2.9 \pm 0.65$ & & NS & \\
\hline PVR dynes $\cdot \mathrm{sec} \cdot \mathrm{cm}^{-5}$ & $901 \pm 318$ & $1318 \pm 597$ & $438 \pm 371$ & 0.058 & 0.06 & $<0.0001$ \\
\hline $\mathrm{PPf}$ & $1.23 \pm 0.21$ & $0.93 \pm 0.22$ & $1.69 \pm 0.32$ & 0.0017 & 0.033 & $<0.0001$ \\
\hline $\begin{array}{ll}P_{\mathrm{a}, \mathrm{O}_{2}} & \mathrm{kPa} \\
\text { torr }\end{array}$ & $\begin{array}{c}7.7 \pm 1.2 \\
58+9\end{array}$ & $\begin{array}{c}10.3 \pm 2.2 \\
78+17\end{array}$ & $10.7 \pm 1.2$ & 0.0002 & 0.0033 & 0.83 \\
\hline $\begin{aligned} & \text { torr } \\
\mathrm{Pa}_{1} \mathrm{CO}_{2} & \begin{array}{l}\mathrm{kPa} \\
\text { torr }\end{array}\end{aligned}$ & $\begin{array}{l}58 \pm 9 \\
4.6 \pm 0.5 \\
34 \pm 4\end{array}$ & $\begin{array}{l}4.6 \pm 0.5 \\
34 \pm 4\end{array}$ & $\begin{array}{l}80 \pm 9 \\
5.2 \pm 0.3 \\
39 \pm 2\end{array}$ & 0.96 & 0.012 & 0.011 \\
\hline
\end{tabular}

Values are presented as mean \pm SD. CTEPH: chronic thromboembolic pulmonary hypertension; PPH: primary pulmonary hypertension; mean $P$ pa: mean pulmonary arterial pressure; systolic $P$ pa: systolic pulmonary arterial pressure; diastolic $P$ pa: diastolic pulmonary arterial pressure; CI: cardiac index; PVR: pulmonary vascular resistance; PPf: fractional pulse pressure; $P \mathrm{a}, \mathrm{O}_{2}$ : arterial oxygen tension; $\mathrm{Pa}, \mathrm{CO}_{2}$ : arterial carbon dioxide tension. *: Kruskal-Wallis analysis of variance with Sheffe's test for multiple comparison. 

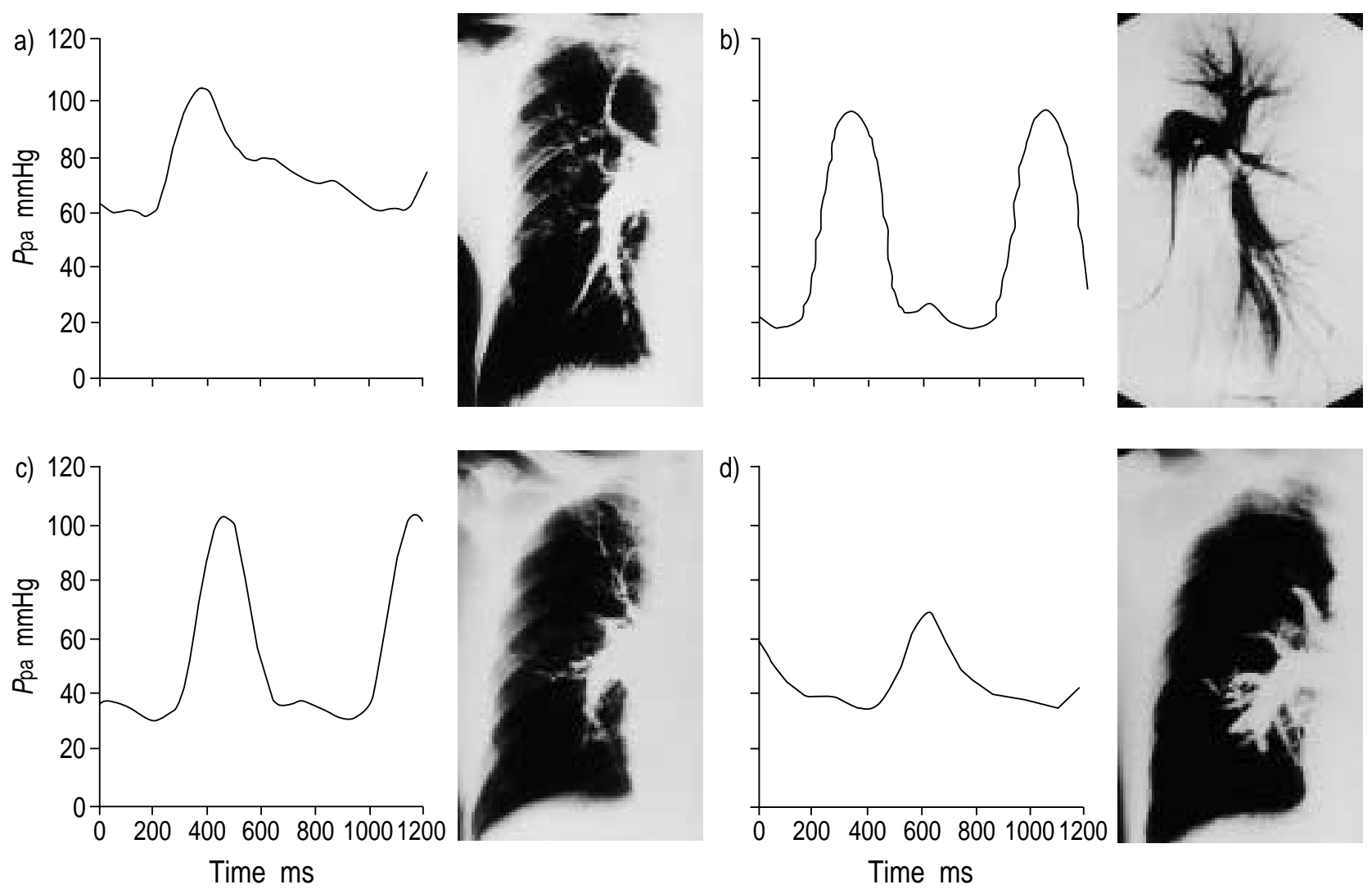

Fig. 2. - The examples of waveforms and angiographic findings. a) Primary pulmonary hypertension: mean pulmonary arterial pressure $(P \mathrm{pa})=74 \mathrm{mmHg}$, pulmonary vascular resistance $(\mathrm{PVR})=2460$ dynes $\cdot \mathrm{sec}^{-} \mathrm{cm}^{-5}$, fractional pulse pressure $(\mathrm{PPf})=0.59$. Marked pruning of the distal vessels was noted while the perfusion scan showed small patchy perfusion defects. b) Pulmonary arteritis: mean $P_{\mathrm{pa}}=44$ $\mathrm{mmHg}, \mathrm{PVR}=433$ dynes $\cdot \mathrm{sec}^{-} \mathrm{cm}^{-5}, \mathrm{PPf}=1.72$. Complete obstruction of the right main pulmonary artery and stenosis of the left lower branch was observed. c) chronic thromboembolic pulmonary hypertension (CTEPH) (survivor): mean $P_{\mathrm{pa}}=50 \mathrm{mmHg}, \mathrm{PVR}=918 \mathrm{dynes}$. sec $\mathrm{cm}^{-5}, \mathrm{PPf}=1.42$. The proximal sites of thrombi were in lobar arteries. d) CTEPH (nonsurvivors): mean $P \mathrm{pa}=44 \mathrm{mmHg}, \mathrm{PVR}=953$ dynes $\cdot \mathrm{sec} \cdot \mathrm{cm}^{-5}, \mathrm{PPf}=0.77$. The thrombi were mostly located in segmental or subsegmental arteries.

(3/14) between 1985 and 1991, and 16.7\% (3/18) from 1992. The mortality of lateral thoracotomy was $12.5 \%$, and that of median sternotomy was $25 \%$ (table 2 ), but preoperative mean $P$ pa was slightly $(\mathrm{p}=0.06)$ higher in median sternotomy $(50 \pm 8 \mathrm{mmHg})$ than that in lateral thoracotomy (45 \pm 7$)$. Five patients died of right heart failure postoperatively, because we could not endarterectomize distal, enough to achieve improvement of pulmonary haemodynamics. One patient died of cardiac tamponade one week after surgery.

As shown in table 2, mean right atrial pressure (mean $P$ ra), diastolic $P$ pa, CI, PVR in nonsurvivors were significantly worse than in survivors. In the survivor in which proximal sites of thrombi were located in lobar arteries, waveform was similar to pulmonary arteritis, and PPf was high (fig. 2c), while in the nonsurvivor in which most thrombi were located in segmental or subsegmental arteries, waveform was similar to $\mathrm{PPH}$, and PPf was low (fig. 2d). The PPf in survivors (1.26士 $0.21)$ was significantly $(p=0.03)$ higher than in nonsurvivors (1.06 \pm 0.16$)$.

Figure 4 plots PVR versus PPf referring to the outcome of surgery. According to the PVR (1100 dynes $\cdot \mathrm{sec} \cdot \mathrm{cm}^{-5}$ ) which was previously reported to be one of predictable risk factors [8], 32 patients were divided into two groups. In patients with a high PVR $\left(>1100\right.$ dynes $\left.\cdot \sec \cdot \mathrm{cm}^{-5}\right)(\mathrm{n}=7)$, the mortality was $57.1 \%$, compared to $8.0 \%$ in those $(n=25)$ with a low PVR $\left(<1100\right.$ dynes $\left.\cdot \mathrm{sec}^{-} \mathrm{cm}^{-5}\right)$. All nonsurvivors had $\mathrm{PPf}<1.2$. PPf was not correlated with PVR ( $\mathrm{r}=-0.04$, NS), and both were included in the multivariate logistic regression for the analysis of mortality. Table 3 shows the results of multivariate logistic regression analysis. PVR was a significant predictor $(p=0.017)$, while PPf was marginally significant $(\mathrm{p}=0.05)$.

In the limited patients with a high PVR ( $>1100$ dynes $\left.\cdot \mathrm{sec} \cdot \mathrm{cm}^{-5}\right)$ the various predictors for mortality between survivors and nonsurvivors were also compared. PPf in nonsurvivors $(1.11 \pm 0.09)$ was significantly $(\mathrm{p}=0.03)$ lower than in survivors $(1.41 \pm 0.12)$. Other predictors ( $P$ ra, diastolic $P$ pa, CI, PVR) did not reach significance $(\mathrm{p}=0.72,0.16,0.16,0.48$, respectively).

\section{Discussion}

This study shows that: 1) PPf in CTEPH was significantly higher than that in PPH and significantly lower than that in pulmonary arteritis with central arterial stenosis, but the distribution of PPfs in CTEPH 


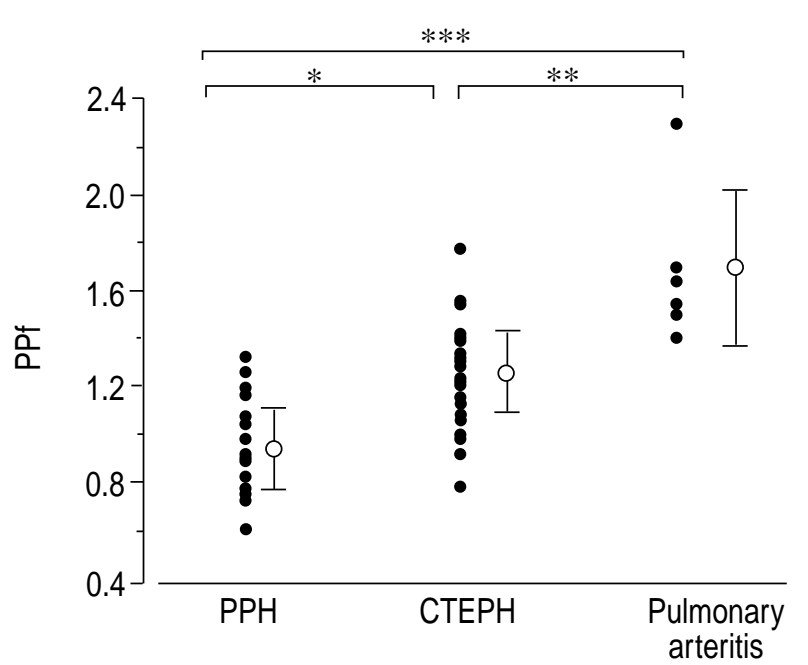

Fig. 3. - Comparison of fractional pulse pressure (PPf) between primary pulmonary hypertension $(\mathrm{PPH} ; \mathrm{n}=18)$, chronic thromboembolic pulmonary hypertension (CTEPH; $\mathrm{n}=32$ ), pulmonary arteritis. *: $\mathrm{p}=0.0017, * *: \mathrm{p}=0.033, * * *: \mathrm{p}<0.00001$ : KruskalWallis analysis of variance with Sheffe's test for multiple comparison. Open circles: mean values; bars: \pm SD.

was wide and overlapped with PPfs in PPH. 2) PPf influenced the operative mortality and low PPf was a useful predictor for the poor outcome of surgery in patients with a high PVR $>1100$ dynes $\cdot \mathrm{sec} \cdot \mathrm{cm}^{-5}$.

The operative mortality associated with pulmonary thromboendarterectomy has markedly decreased at University California at San Diego [5]. The mortality in other institutions, however, was still high (16-23\%) $[7-12,15]$. Severe haemodynamic disorder (PVR $>1100$ dynes $\cdot \mathrm{sec} \cdot \mathrm{cm}^{-5}$ ) predicted the high operative mortality at both Illinois study [8] and the present study. The most important cause of mortality for pulmonary thromboendarterectomy is inability to reduce pulmonary arterial pressure as a result of distal disease that proves inaccessible, and/or secondary pulmonary hypertensive change $[4,9]$. Recently it was reported that

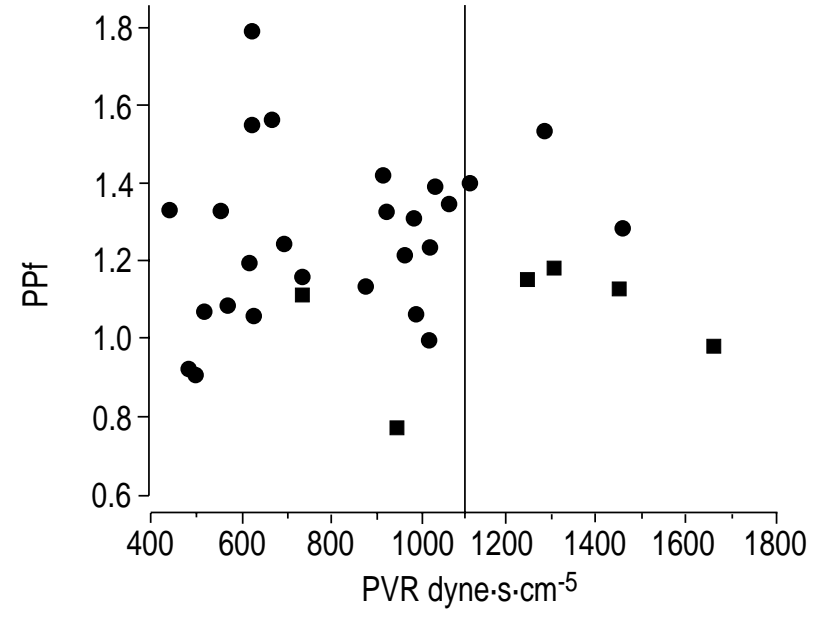

Fig. 4. - The outcome of surgery for chronic thromboembolic pulmonary hypertension (CTEPH) (pulmonary vascular resistance) versus fractional pulse pressure (PPf)). Mortality rate was $18.8 \%$. In patient $(\mathrm{n}=7)$ with a high PVR $\left(>1100\right.$ dynes $\left.\cdot \mathrm{sec} \cdot \mathrm{cm}^{-5}\right)$, the mortality was $57.1 \%$, compared to $8.0 \%$ in those $(n=25)$ with a low PVR $\left(<1100\right.$ dynes $\left.\cdot \mathrm{sec} \cdot \mathrm{cm}^{-5}\right)$. All nonsurvivors had a low PPf $(<1.2)$. PPf was not correlated with PVR $(n=32, r=-0.04)$. : survivors $(\mathrm{n}=26) ; \mathbf{\square}$ : nonsurvivors $(\mathrm{n}=6)$.

the pulsatility as the ratio of pulse pressure to mean pressure (PPf) in CTEPH was larger than in PPH due to the difference of primary involved lesions [19]. The present authors reassessed their data and hypothesized that PPf might be low in CTEPH with inaccessible distal thrombi and/or secondary pulmonary hypertensive change. Although the difference of PPf was found among various pulmonary hypertensive diseases, the most significant findings were that PPfs were widely distributed in CTEPH. PPf in addition to PVR was useful in predicting operative mortality, especially in patients with severe haemodynamic impairment. Several issues need to be considered in the interpretation of these results.

Firstly, larger PPf was shown in CTEPH compared to PPH. This is partly consistent with the results of

Table 2. - Comparison of preoperative parameters between survivors and nonsurvivors

\begin{tabular}{|c|c|c|c|}
\hline Parameters & Survivors & Nonsurvivors & p-value* \\
\hline Subjects $n$ & 26 & 6 & \\
\hline Age yrs & $52 \pm 13$ & $48 \pm 18$ & 0.66 \\
\hline Mean $P_{\text {sa }} \mathrm{mmHg}$ & $91 \pm 10$ & $94 \pm 12$ & 0.40 \\
\hline Duration of symptoms months & $27 \pm 20$ & $31 \pm 32$ & 0.75 \\
\hline Mean $P$ ra $\mathrm{mmHg}$ & $3 \pm 3$ & $7 \pm 3$ & 0.013 \\
\hline Mean $P$ pa $\mathrm{mmHg}$ & $45 \pm 8$ & $51 \pm 10$ & 0.13 \\
\hline Systolic $P$ pa $\mathrm{mmHg}$ & $82 \pm 17$ & $87 \pm 18$ & 0.51 \\
\hline Diastolic $P$ pa $\mathrm{mmHg}$ & $25 \pm 5$ & $33 \pm 6$ & 0.014 \\
\hline CI $\mathrm{L} \cdot \mathrm{min}^{-1} \cdot \mathrm{m}^{-2}$ & $2.6 \pm 0.5$ & $1.9 \pm 0.4$ & 0.003 \\
\hline PVR dynes $\cdot \mathrm{sec} \cdot \mathrm{cm}^{-5}$ & $821 \pm 266$ & $1224 \pm 337$ & 0.016 \\
\hline PPf & $1.26 \pm 0.21$ & $1.06 \pm 0.16$ & 0.03 \\
\hline$P \mathrm{a}, \mathrm{O}_{2} \mathrm{kPa}$ & $7.5 \pm 1.0$ & $8.5 \pm 1.6$ & 0.19 \\
\hline torr & $57 \pm 8$ & $64 \pm 12$ & \\
\hline Operative approach (median : lateral) & $12: 14$ & $4: 2$ & 0.37 \\
\hline
\end{tabular}

Values are presented as mean \pm SD. Duration of symptoms: duration of symptoms between onset and operation; mean $P$ sa: mean systemic arterial pressure; mean $P_{\text {ra: }}$ mean right atrial pressure; $P$ pa: pulmonary arterial pressure; CI: cardiac index; PVR: pulmonary vascular resistance; PPf: fractional pulse pressure; $P \mathrm{a}_{2} \mathrm{O}_{2}$ : arterial oxygen tension; median: median sternotomy; lateral: lateral thoracotomy. *: Mann-Whitney U-test and Chi-squared test, appropriate. 
Table 3. - Multivariate logistic regression analysis

\begin{tabular}{lcc}
\hline & \multicolumn{2}{c}{ Mortality $(\mathrm{n}=7)$} \\
\cline { 2 - 3 } Variables & Coefficient & p-value \\
\hline PVR & 0.007 & 0.017 \\
PPf & -11.242 & 0.052 \\
Constant & 4.7746 & \\
\hline
\end{tabular}

PVR: pulmonary vascular resistance; PPf: fractional pulse pressure.

Nakayama et al. [19]. However, a clear distinction could not be shown between CTEPH and PPH by PPf, because the present data were widely distributed, in contrast to the data of NAKAYAMA et al. [19]. Both studies hypothesized that CTEPH should have stiffness or high resistance in proximal arteries, whereas $\mathrm{PPH}$ should have high resistance in peripheral arteries, and these differences in the primary lesions would make arterial pulse pressure relative to mean arterial pressure larger in CTEPH than in PPH. However CTEPH could have secondary hypertensive change in the peripheral artery and/or distal thrombi. The present study might have included more distal diseases, because mean PPf in CTEPH in this study is significantly lower than in NAKAYAMA et al. [19] $(1.23 \pm 0.21$ and $1.41 \pm 0.20$ respectively, $\mathrm{p}=0.0003$, unpaired t-test).

Secondly, only PPf was used to analyse pulsatile components of right ventricular afterload. Recently CASTELAIN et al. [28] reported that CTEPH and PPH had similar PPf using high fidelity pressure catheter. They also quantified wave reflection [16, 28-33] by measuring $t$, i.e. the time between pressure upstroke and systolic inflection point $(P \mathrm{i}) ; \Delta P$, i.e. systolic $P$ pa minus $P_{\mathrm{i}}$; and augmentation index ( $\Delta P /$ pulse pressure) [30] which quantifies the extent of wave reflection. They showed that CTEPH had shorter $t$ i and higher $\Delta P /$ pulse pressure, and suggested that CTEPH had increased and anticipated wave reflection compared to PPH. The difference between two studies might arise from the difference of measurements. High-fidelity pressure catheter was not used and the wave reflection was not quantified. Although it is agreed that wave reflection is different between CTEPH and PPH, CASTELAIN et al. [28] used small number of patients (PPH $n=7, \mathrm{CTEPH}$ $\mathrm{n}=7)$ and, mean PPf (0.97) in CTEPH was larger than PPH (0.89) in their report. In large series, PPf in CTEPH could be significantly larger than PPH, although CTEPH could not be differentiated from PPH by only PPf.

Stiffening of the proximal arteries by the thrombi and arteritis could increase characteristic impedance of the pulmonary artery. Several investigators have attributed the increase of pulse pressure to the decreased arterial compliance and increased characteristic impedance in systemic arteries [32-37]. Similarly GRANT and coworkers $[16,17]$ showed that stiffening of the pulmonary artery increased pulse pressure. It is unlikely that the reflection wave is related to increased pulse pressure in pulmonary arteritis, because in their other experiment the ensnarement of pulmonary artery increased pulse pressure and characteristic impedance, but had little effect on wave reflection $[16,18]$. Both increased characteristic impedance and early and increased reflection wave could accentuate pulse pressure and PPf in CTEPH.

Thirdly, low PPf was shown as the possible preoperative risk factor for pulmonary thromboendarterectomy in patients with a high PVR. HARTz et al. [8] reported that the patients with high PVR $>1100$ dynes $\cdot \mathrm{sec} \cdot \mathrm{cm}^{-5}$ have a high likelihood of operative mortality, and perhaps should not undergo pulmonary thromboendarterectomy except at limited institutions where the operations are performed frequently. It was shown that PVR is more useful in predicting the operative mortality than PPf. However, thromboendarterectomy has been performed even in high risk patients, because the mortality of lung transplantation for pulmonary hypertension is still high [15, 38], and furthermore it has not been performed in Japan. More precise operative criteria in infrequently performed institutions are needed. It is important to accurately evaluate distal thrombi and secondary pulmonary hypertensive change. Nevertheless, it is difficult to make a precise diagnosis by angiography and even by angioscopy $[6,39]$. The assessment of PPf as well as angiogram could be helpful to decide the accessibility to thrombi. This study suggests that in the patient with only a few thrombi and high PVR, low PPf might be related to secondary pulmonary hypertensive change and/or distal thrombi, resulting in high operative mortality.

Finally, the most important limitation in this study is that a fluid-filled system was used to record pulmonary arterial pressure. As recorded pressures, the catheter was fluoroscopically placed to minimize catheter whip to keep that artifact at minimum. If a high fidelity pressure transducer could have been used, the recorded pressure waveform would have been more accurate. However, the authors think the fluid-filled system is simpler and easier to use than high fidelity pressure system. Considering PPf in addition to pulmonary vascular resistance and angiograms gives important and useful information for clinical differential diagnosis of pulmonary hypertensive diseases.

It has been reported that pulmonary artery impedance and pulsatile properties must be taken into consideration to understand right ventricular-pulmonary artery coupling $[16,33]$. The data are limited in fractional pulse pressure, but more precise assessment of pulsatile components using high-fidelity catheter as well as large series study for the influence of fractional pulse pressure to surgical outcome will be needed.

\footnotetext{
Acknowledgements. The authors thank W.W. Wagner, Jr. for helpful criticism of the manuscript.
}

\section{References}

1. Moser KM, Spragg RG, Utley J, Daily PO. Chronic thrombotic obstruction of major pulmonary arteries: results of thromboendarterectomy in 15 patients. Ann Intern Med 1983; 99: 299-305. 
2. Daily PO, Dembitsky WP, Iversen S, Moser KM, Auger W. Risk factors for pulmonary thromboendarterectomy. J Thorac Cardiovasc Surg 1990; 99: 670 678.

3. Moser KM, Auger WR, Fedullo PF, Jamieson SW. Chronic thromboembolic pulmonary hypertension: clinical picture and surgical treatment. Eur Respir $J$ 1992; 5: 334-342.

4. Jamieson SW, Auger WR, Fedullo PF, et al. Experience and results with 150 pulmonary thromboendarterectomy operations over a 29 -month period. J Thorac Cardiovasc Surg 1993; 106: 116-127.

5. Jamieson SW. Treatment of pulmonary hypertension due to chronic pulmonary thromboembolism. Jpn J Phlebol 1995; 6: 1-12.

6. Fedullo PF, Auger WR, Channick RN, Moser KM, Jamieson SW. Chronic thromboembolic pulmonary hypertension. Clin Chest Med 1995; 16: 353-374.

7. Mayer E, Dahm M, Hake U, et al. Mid-term results of pulmonary thromboendarterectomy for chronic pulmonary hypertension. Ann Thorac Surg 1996; 61: 1788-1792.

8. Hartz RS, Byrne JG, Levtsky S, Park J, Rich S. Predictors of mortality in pulmonary thromboendarterectomy. Ann Thorac Surg 1996; 62: 1225-1260.

9. Tanabe N, Okada O, Nakagawa Y, et al. The efficacy of pulmonary thromboendarterectomy on long-term gas exchange. Eur Respir J 1997; 10: 2066-2072.

10. Nakajima N, Masuda M, Mogi K. The surgical treatment for chronic pulmonary thromboembolismour experience and current review of the literature. Ann Thorac Cardiovasc Surg 1997; 3: 15-21.

11. Chitwood WR, Lyerly HK, Sabiston DC. Surgical management of chronic pulmonary embolism. Ann Surg 1985; 201: 11-26.

12. Jault F, Cabrol C. Surgical treatment for chronic pulmonary thromboembolism. Herz 1989; 14: 192-196.

13. Nakajima $\mathrm{N}$, Ando $\mathrm{M}$, Adachi $\mathrm{S}$, Kasegawa $\mathrm{H}$. Surgical treatment of pulmonary thromboembolism. Jpn J Thorac D 1988; 26: 487-492.

14. Nakagawa Y. Surgery for chronic thromboembolic pulmonary hypertension. International Congress of Phlebology Bologna, Manduzzi Editore, 1996 pp. 393-396.

15. Simonneau G, Azarian R, Brenot F, Dartevelle PG, Musset D, Duroux P. Surgical management of unresolved pulmonary embolism: a personal series of 72 patients. Chest 1995; 107: 52s-55s.

16. Grant BJB, Lieber BB. Clinical significance of pulmonary arterial input impedance. Eur Respir J 1996; 9: 2196-2199.

17. Fitzpatrick JM, Grant BJB. Effects of pulmonary vascular obstruction on right ventricular afterload. $\mathrm{Am}$ Rev Respir Dis 1990; 141: 944-952.

18. Grant BJB, Balderman SC. Independent effects of mean pulse pressure on right ventricular hypertrophy in rats. Circulation 1994; 90: 1418.

19. Nakayama Y, Nakanishi N, Sugimachi M, et al. Characteristics of pulmonary artery pressure waveform for differential diagnosis of chronic pulmonary thromboembolism and primary pulmonary hypertension. J Am Coll Cardiol 1997; 29: 1311-1316.

20. Moser KM, Bloor CM. Pulmonary vascular lesions occurring in patients with chronic major vessel thromboembolic pulmonary hypertension. Chest 1993; 103: 685-692.

21. Okubo S, Kunieda T, Ando M, Nakajima N, Yutani
C. Idiopathic pulmonary arteritis with chronic cor pulmonale. Chest 1988; 94: 665-666.

22. Uchiyama R, Shishihara T, Tanabe N, et al. A case of idiopathic pulmonary arteritis with positive antimyeloperoxidase antibodies. Jpn J Thorac D 1995; 33: 569-575.

23. Lupi EH, Sanchez GT, Horwitz S, Gutierrez EF. Pulmonary artery involvement in Takayasu's arteritis. Chest 1975; 67: 69-74.

24. Yamato M, Lecky JW, Hiramatsu K, Kohda E. Takayasu arteritis: radiographic and angiographic findings in 59 patients. Radiol 1986; 161: 329-334.

25. Kerr KM, Auger WR, Fedullo PF, Channick RH, Yi ES, Moser KM. Large vessel pulmonary arteritis mimicking chronic thromboembolic disease. Am J Respir Crit Care Med 1995; 152: 367-373.

26. Auger WR, Fedullo PF, Moser KM, Buchbinder M, Peterson KL. Chronic major-vessel thromboembolic pulmonary artery obstruction: appearance at angiography. Radiology 1992; 182: 393-398.

27. Hugh-Jones P. A simple standard exercise test and its use for measuring exertion dyspnoea. BMJ 1952: 6571.

28. Castelain V, Herve P, Jagot Y, et al. Pulse pulmonary arterial pressure and wave reflection on chronic pulmonary thromboembolism and primary pulmonary hypertension, before and nitric oxide. Am J Respir Crit Care Med 1998; 157: A593.

29. Westerhof N, Sipkema P, van den Bos GC, Elzinga G. Forward and backward waves in the arterial system. Cardiovasc Res 1972; 6: 648-656.

30. Murgo JP, Westerhof N, Giolma JP, Altobelli SA. Aortic input impedance in normal man: relationship to pressure wave forms. Circulation 1980; 62: 105-116.

31. Laskey WK, Kussmaul WG. Arterial wave reflection in heart failure. Circulation 1987; 75: 711-722.

32. Kussmaul WG, Noordergraaf A, Laskey WK. Right ventricular-pulmonary arterial interactions. Ann Biomed Eng 1992; 20: 63-80.

33. Murpurgo M, Jezek V, Ostadal B. Pulmonary input impedance or pulmonary vascular resistance? Monaldi Arch Chest Dis 1995; 50: 282-285.

34. Morita S, Kuboyama I, Asou T, et al. The effect of extraanatomic bypass on aortic input impedance in open chest dogs. Should the vascular prosthesis be compliant to unload the left ventricle? J Thorac Cardiovasc Surg 1991; 102: 774-783.

35. Urshel CW, Covell JW, Sonnenblick EH, Ross J, Braunwald E. Effect of decreased aortic compliance on performance of the left ventricle. Am J Physiol 1968; 214: 298-304.

36. O'Rourke MF. Steady and pulsatile energy losses in the systemic circulation under normal conditions and in simulated arterial disease. Cardiovasc Res 1967; 1: 313-316.

37. Randall OS, van den Boss GC, Westerhof N . Systemic compliance: does it play a role in the genesis of essential hypertension? Cardiovasc Res 1984; 18: 455-462.

38. Katayama Y, Cremona G, Wallwork J, Higenbottam T. Transplantation for primary pulmonary hypertension. In: Rubin LJ and Rich S, ed. Primary pulmonary hypertension. New York, Marcel Dekker Inc., 1997; 287-304.

39. Shure D, Gregoratos G, Moser KM. Fiberoptic angioscopy: Role in the diagnosis of chronic pulmonary arterial obstruction. Ann Intern Med 1985; 103: 844850 . 